\title{
OBSERVATIONS OF THE DIRECTIONAL SPECTRUM RELAXATION OF WAVEFIELDS IN SLOWLY AND RAPIDLY TURNING WINDS
}

\author{
I.K. TSANIS* \\ F. BRISETTE**
}

* Department of Civil Engineering, McMaster University, Hamilton
Ontario, Canada L8S $4 L 7$
$* *$ Ecole de Technologie Supérieure, Université du Québec
Montréal, Canada H3C 1K3

* to whom all correspondence should be addressed e-mail: tsanis@water.eng.mcmaster.ca

\begin{abstract}
A so called "Exact Form" of the Maximum Likelihood Method is used to obtain directional spectrum estimates from a 3-meter NDBC discus buoy, part of the Surface Wave Dynamics Experiment (SWADE) field array. The method was used to look at the response of wavefields to turning winds with various wind shift gradients. For slowly turning winds, the spectrum was found to smoothly adjust to the wind changes. As the wind shift gradient increased, a portion of the spectral energy was found to be decoupled from the wind while the bulk of the spectrum smoothly adjusted to the new wind direction. Finally, for even larger wind shift gradients, the preexisting spectrum was completely decoupled from the wind and decayed separately, as a new spectrum consistent with the wind direction was generated. These observations confirm theoretical results previously obtained from a third generation wave model. The relaxation of waves in turning winds was investigated using a simple relaxation model. Correlation coefficients obtained in this study are higher than previously published studies, especially for lower values of the wave age, and a relationship between the relaxation parameter and the wave age is observed.
\end{abstract}

KEYWORDS: water waves, directional spectra, turning winds, ocean, physical oceanography

\section{INTRODUCTION}

A representation of the wave energy as a function of frequency, the frequency spectrum, can easily be obtained since it can be extracted from a single record of the water surface elevation at one given location. But surface gravity water waves are not long-crested but rather propagate with appreciable angular spreading about their mean direction. The assumption of a single direction of propagation, common to most engineering applications can potentially lead to significant errors, especially in cases of mixed seas where energy peaks can come from different directions. The specification of wave direction of propagation is by no means simple and the physics leading to this angular spread of energy are not well understood, the main effects being the inherent variability of the source function, and the non-linear effects between wave components and those associated with wave breaking. A more accurate representation of the wave field in the frequency-direction domain will lead to a better understanding of the wave processes, which in turn 
will help engineers dealing with coastal applications. Waves are fundamental in shaping coastlines, determining the geometry and composition of beaches, and can have potentially devastating effects on man-made structures both offshore and in coastal areas. Wave climates are important for the design of harbors, waterways, and shore protection measures, where a significant part of the wind energy transmitted to waves is dissipated. The accurate estimation of wave energy and direction of propagation is important for the handling and design of marine vehicles, and has many applications for the offshore industry, particularly the petroleum industry. These applications encompass engineering design, operational efficiency, safety and protection of the environment.

A better representation of the surface structure of random seas will also benefit scientists and limnologists by leading to improved hindcasting and forecasting methods. This paper specifically focuses on one aspect of wave processes, by looking at the detailed structure of the wave directional spectrum in cases of slowly to rapidly turning winds.

\section{WAVE DIRECTIONAL SPECTRUM ESTIMATION}

The two-dimensional spectrum $\mathrm{S}(\theta, \omega)$, which is a function of both the frequency $\omega$ and direction $\theta$ is generally expressed as the product of the onedimensional frequency spectrum $F(\omega)$ and a normalized directional spreading function $\mathrm{D}(\theta, \omega)$ :

$$
\mathrm{S}(\theta, \omega)=\mathrm{F}(\omega) \mathrm{D}(\theta, \omega)
$$

where the function $\mathrm{D}(\theta, \omega)$ specifies the directional spreading of energy at each frequency band of the spectrum. The main problem in the determination of the directional spectrum $S(\theta, \omega)$ lies in the evaluation of the normalized spreading function $\mathrm{D}(\theta, \omega)$.

Obtaining directional spectrum estimates is not a simple task as many methods are now available, potentially giving significantly different results. Of all the methods of estimating the wave directional spectrum, the Longuet-Higgins et al. (1963) method is probably still the one most widely in use. Using pitch-roll data, the method allows the first 2 coefficients of the Fourier series of the angular distribution of energy to be calculated. The estimate can be expressed as:

$$
\begin{aligned}
\mathrm{S}\left(\omega_{\mathrm{k}}, \theta\right) \approx \hat{\mathrm{S}}\left(\omega_{\mathrm{k}}, \theta\right)=\mathrm{a}_{0}+\frac{2}{3}\left(\mathrm{a}_{1} \cos \theta+\mathrm{b}_{1} \sin \theta\right)+ \\
+\frac{1}{6}\left(\mathrm{a}_{2} \cos 2 \theta+\mathrm{b}_{2} \sin 2 \theta\right)
\end{aligned}
$$

where the Fourier coefficients are a function of the cross-spectra between the heave, pitching and rolling signals. This method has been shown to give smeared estimates of the true spectrum and is clearly not adequate in reconstructing the entire directional distribution. Nevertheless, following Kuik et al. (1988), the first 2 Fourier coefficients can still be used to calculate model-free directional parameters such as the mean wave direction, RMS spread and skewness of the directional distribution. However, to obtain detailed directional information, it is necessary to reconstruct the entire directional spectrum. Since Longuet-Higgins et al. (1963), many methods have been proposed to calculate directional spectrum estimates. In a recent review of some of these methods, Brissette and Tsanis (1994) concluded that although precise estimates could be obtained from these methods in some cases, the general picture was that the estimates were dependent on factors such as background noise, wavenumber considered, and could give rise to numerical problems. They then went on to propose an "exact form" of the Maximum Likelihood Method (Christopoulos et al., 1998), which outperformed the other methods over more than 80 test cases involving both unimodal and bimodal angular distributions of energy. The new method expresses the MLM estimate as a function of the underlying true directional spectrum. Using an inversion of this expression, the estimate of the underlying directional spectrum can be calculated using the standard Lagrange multiplier minimization approach. The obtained estimate is fully consistent with the Cross-Power-Spectral data and is the only possible estimate consistent with the MLM formulation. The directional estimate is given in vectorized form as:

$$
\underline{\mathrm{S}}=\frac{\operatorname{inv}\left(\left(\left(\frac{\mathrm{C}^{-1} \mathrm{X}\left(\theta_{\mathrm{i}}\right)}{\mathrm{X}\left(\theta_{\mathrm{i}}\right)^{\mathrm{H}} \mathrm{C}^{-1} \mathrm{X}\left(\theta_{\mathrm{i}}\right)}\right) \underline{\mathrm{X}}^{\mathrm{T}}\right)^{.2}\right)}{\mathrm{X}\left(\theta_{\mathrm{i}}\right)^{\mathrm{H}} \mathrm{C}^{-1} \mathrm{X}\left(\theta_{\mathrm{i}}\right)}
$$

where inv denotes the inverse of the matrix within the brackets and the exponent ".2" denotes an element-by-element operation. $\mathrm{C}^{-1}$ is the inverse of the Cross-Power-Spectral-Density (CPSD) matrix and $\mathrm{X}\left(\theta_{\mathrm{i}}\right)$ equal to (for heave-pitch-roll data):

$$
X=\left[\begin{array}{c}
1 \\
i k \cos \theta \\
i k \sin \theta
\end{array}\right]
$$


with $\mathrm{k}$ the wavenumber defined as:

$$
\mathrm{k}=\left(\frac{\mathrm{C}_{22}+\mathrm{C}_{33}}{\mathrm{C}_{11}}\right)^{1 / 2}
$$

where $\mathrm{C}_{\mathrm{ii}}$ is a cross-spectra value and the subscripts 1,2 and 3 respectively refer to the heave, pitching and rolling signals.

All directional estimates were calculated using Eq. (3), which was shown to produce the highest possible directional resolution for a three measurements signal of the water surface. Eq. (3) defines the only solution of the wave directional spectrum consistent with the Maximum Likelihood Method formulation. This estimate is fully consistent with the input CPSD matrix (Christopoulos et al., 1998).

\section{DATA ANALYSIS}

The field data used in this work comes from a NDBC pitch-roll-heave buoy part of the Surface Wave Dynamics Experiment described in Weller et al. (1991). The SWADE experiment was designed to provide extensive spatial and temporal coverage on the east coast of the Atlantic Ocean. The SWADE field observation period ran from October 1990 to March 1991 during which data was gathered almost continually. NDBCSWADE data was made available to this research through the National Data Buoy Center (NDBC), Washington D.C.

Data pertaining to this paper comes from the Discus-North buoy (NDBC 44001) shown in Figure 1, which is a 3-meters NDBC Discus Directional buoy. The Discus-N buoy is located at $73^{\circ} 48.9^{\prime} \mathrm{W}$ longitude and $38^{\circ} 11.6^{\prime} \mathrm{N}$ latitude, at the edge of the continental shelf offshore of Virginia. All the data analysed and presented in this paper comes from the Discus- $\mathrm{N}$ buoy. Detailed information pertaining to directionalwave measurements with NDBC Discus Buoys,

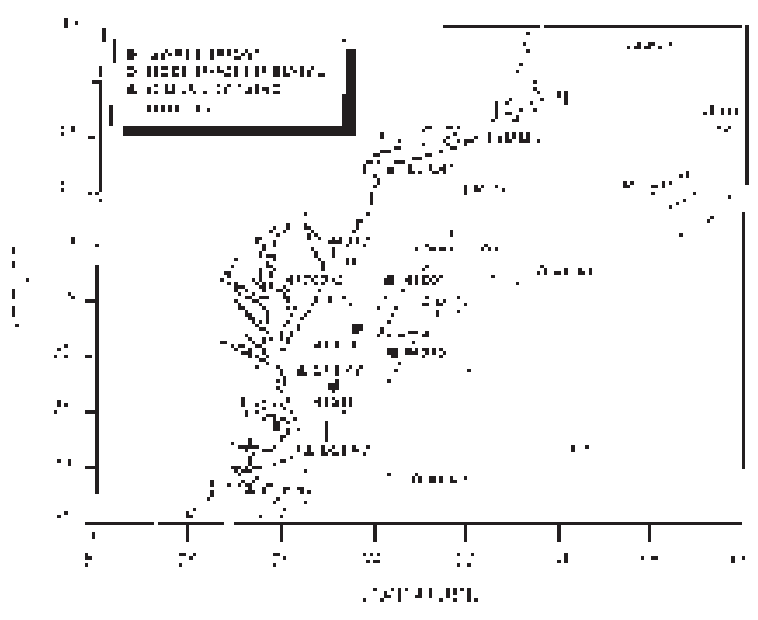

Figure 1. Geographic location of the SWADE experiment and location of various buoys

(Weller et al., 1991).

data acquiring, processing and transmitting can be found in Steele, Lau and Hsu (1985) and Steele et al. (1990). Following Anctil et al. (1992), NDBC data was checked for anomalies in the buoy wave following capacities, and corrected if needed by insuring that phase shifts between the water elevation and surface slopes lead to imaginary only cross-spectra. Cross-spectra for the heave, pitching and rolling signals are one hour averages given in frequency bands of $0.01 \mathrm{~Hz}$ (up to $0.35 \mathrm{~Hz}$ ), giving spectral estimates with 72 degrees of freedom. Wind speed and directions are 8.5 minutes averages taken at a height of $4 \mathrm{~m}$ above the water surface.

During a period starting October 20, 1990 and ending October 30, 1990, three severe storms swept the SADE location. Wind speed and wind direction for the entire duration of the events are shown in Figure 2a. All three storm episodes had

Table 1. Cases Selected

\begin{tabular}{|c|c|c|c|c|c|c|c|}
\hline \multirow{2}{*}{$\begin{array}{c}\text { CASE } \\
\text { \# }\end{array}$} & \multirow{2}{*}{$\begin{array}{l}\text { START (GMT) } \\
\text { yymmddhh }\end{array}$} & \multirow{2}{*}{$\begin{array}{c}\text { END (GMT) } \\
\text { yymmddhh }\end{array}$} & \multirow{2}{*}{$\begin{array}{c}\text { DUR. } \\
\text { hrs }\end{array}$} & \multicolumn{2}{|c|}{ mean $\left|\partial \theta_{w} / \partial t\right|$} & \multicolumn{2}{|c|}{$\max \left|\partial \theta_{w} / \partial t\right|^{*}$} \\
\hline & & & & $\operatorname{rad~s}^{-1}$ & ${ }^{\circ} \mathrm{hr}^{-1}$ & $\operatorname{rad~s}^{-1}$ & ${ }^{\circ} \mathrm{hr}^{-1}$ \\
\hline $\mathrm{C} 1$ & 90102000 & 90102123 & 48 & $2.8 \times 10^{-5}$ & 5.7 & $3.4 \times 10^{-5}$ & 7 \\
\hline $\mathrm{C} 2$ & 90102318 & 90102411 & 18 & $4.7 \times 10^{-5}$ & 9.6 & $1.1 \times 10^{-4}$ & 22 \\
\hline $\mathrm{C} 3$ & 90102721 & 90102822 & 26 & $5.9 \times 10^{-5}$ & 12.3 & $1.5 \times 10^{-4}$ & 3 \\
\hline
\end{tabular}

${ }^{*} \max \left|\partial \theta_{\mathrm{w}} / \partial \mathrm{t}\right|$ is defined over a 5 hours period $10^{-5}$ 


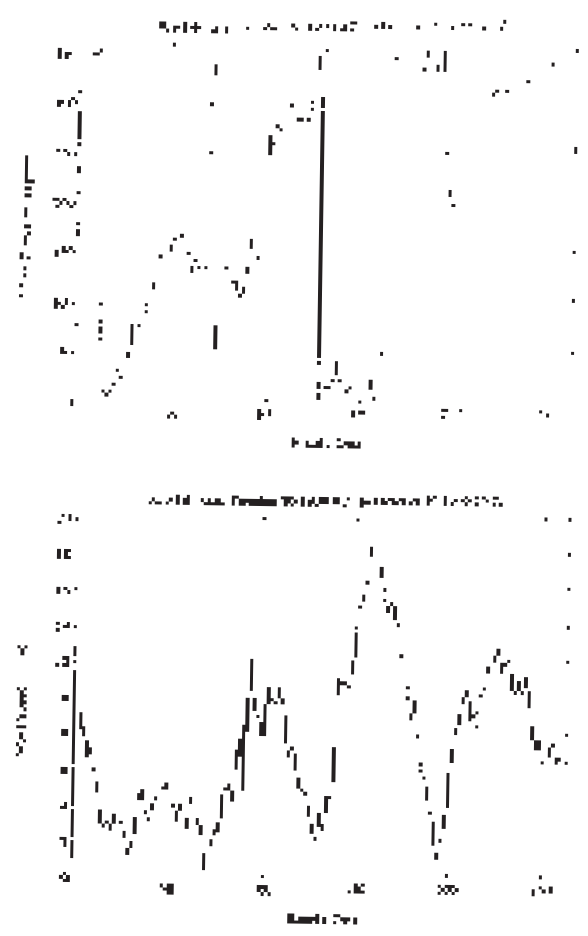

(a)
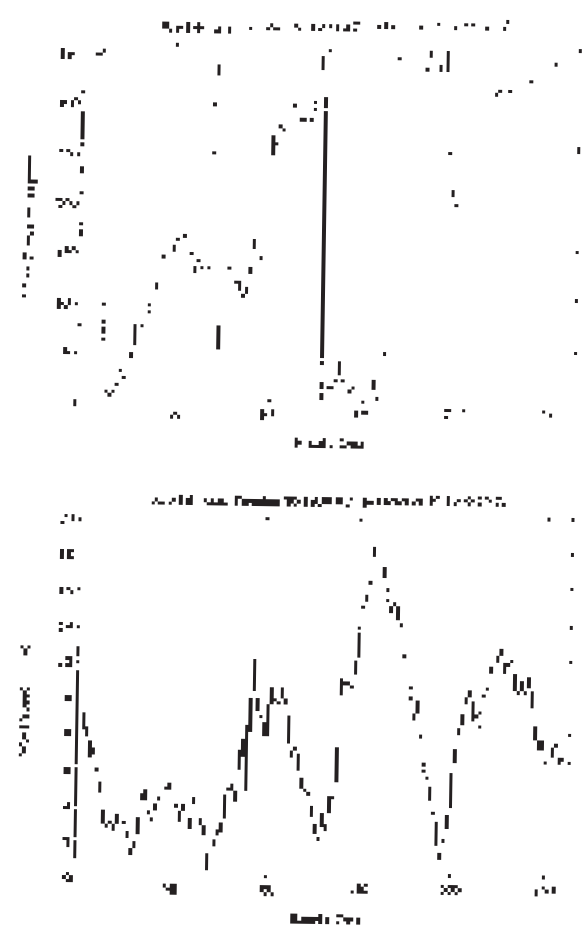

(c)

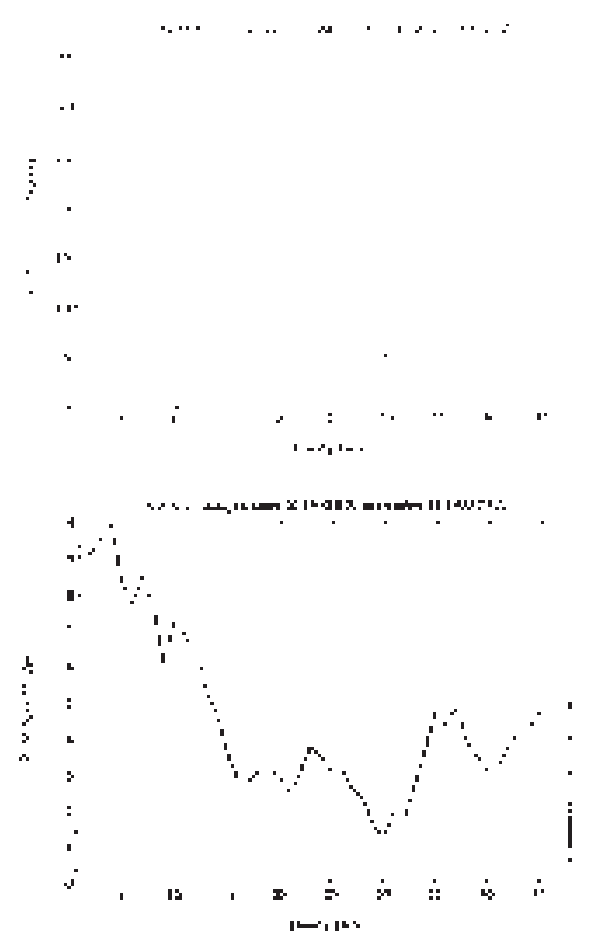

(b)

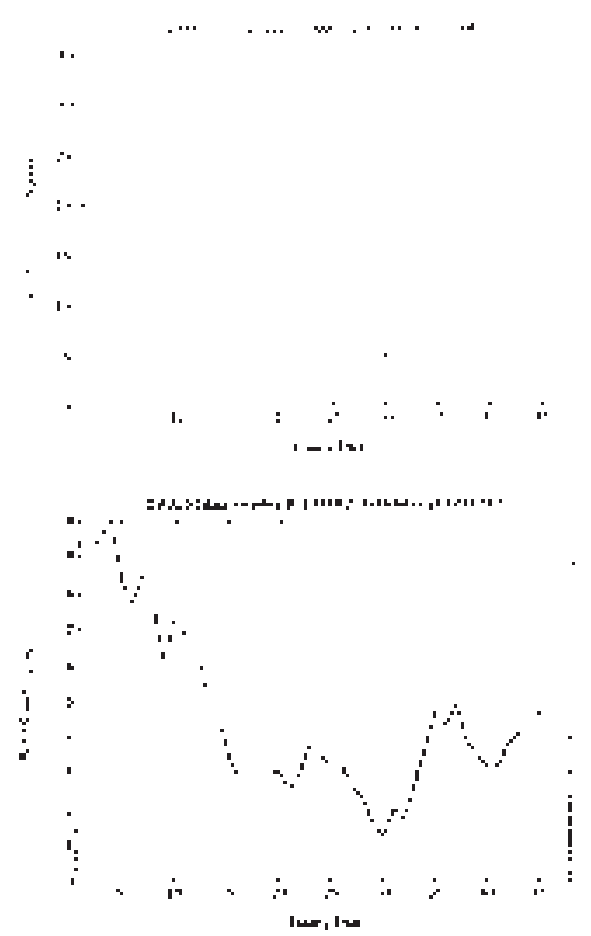

(d)

Figure 2. Time series of wind direction (top) and wind speed (bottom). The wind data (taken at $4 \mathrm{~m}$ ) represent 8.5 minutes averages every hour.

(a): storm period of October 20-October 30; (b): first selected case, C1; (c): second selected case, C2; (d) third selected case, C3. 
wind speed in excess of $12 \mathrm{~m} \mathrm{~s}^{-1}$ and significant wave heights Hs of up to $6 \mathrm{~m}$ for the most severe storm. The plot of the wind direction shown in Figure 2a indicates that many episodes of turning winds can be isolated during the 11 days period. In order to investigate more closely the directional spectrum response to turning winds, three cases were isolated from the 11 days period, and separately analysed. Table 1 gives information on all three selected cases and Figures 2b, $2 c$ and $2 d$ display the wind history for all three cases. These three cases were selected because they all presented different characteristics. The first case (C1) represents a wind turning over $200^{\circ}$ at a roughly constant angular speed over the entire period of 48 hours. The second case (C2) depicts a wind turning by about $120^{\circ}$ over an 8 hours period. Finally the third case (C3) represents a more complex situation with the wind rapidly shifting from $330^{\circ}$ to $200^{\circ}$ in less than three hours, builds up momentum from that direction for about 13 hours and rapidly shifts again from $200^{\circ}$ to $300^{\circ}$. The wind is roughly constant only for the second case.

\section{RESULTS}

\section{Case 1 (C1)}

Figure 3 a presents a contour plot of the evolution of the frequency spectrum over the 48 hours period. The main feature of this case is the arrival of a swell in the area at around the 22 hour mark. The evolution of the directional spectrum at a frequency of $0.1 \mathrm{~Hz}$, which is the frequency of the swell, is shown in Figure 3b. The figure shows that the swell, coming from about $130^{\circ}$, is essentially unaffected by the relatively weak winds $\left(3-4 \mathrm{~m} \mathrm{~s}^{-1}\right)$. Nevertheless, the angular distribution of energy is observed to be slightly skewed toward the wind. A similar plot is presented in Figure $3 \mathrm{c}$ for a frequency of $0.15 \mathrm{~Hz}$. Figure $3 \mathrm{c}$ presents the evolution of the directional spectrum normalized to unity, thus becoming a plot of the spreading function at this given frequency. The wind direction is presented by the superposed continuous solid line. It can be seen from this Figure that the wave direction essentially coincides with the wind direction until about 24 hours, at which time the swell, with energy in the same frequency band, creates bimodality in the energy distribution. The wind sea energy still propagates with the wind until its direction coincides with the swell, at which point both systems coalesce.
Figure $3 \mathrm{~d}$ gives results for a frequency of $0.2 \mathrm{~Hz}$. The wave direction in that frequency band coincides with the wind direction until the arrival of the swell (the swell has little or no energy in this frequency band), at which point the waves turn to be initially aligned perpendicular to the incoming swell. The same behaviour is also expressed at higher frequencies, as shown in Figure 4, which presents the mean wave direction at discrete frequencies of $0.1,0.15,0.2,0.25,0.3$ and $0.35 \mathrm{~Hz}$, plotted with the wind direction. The mean direction $\theta_{\mathrm{m}}$ is defined following Kuik et al. (1988), as the vectorial mean of the directional distribution, which can also be expressed in terms of the first Fourier coefficients:

$$
\theta_{\mathrm{m}}(\omega)=\operatorname{atan}\left(\frac{\int_{0}^{2 \pi} \sin \theta \mathrm{S}(\theta, \omega) \mathrm{d} \theta}{\int_{0}^{2 \pi} \cos \theta S(\theta, \omega) \mathrm{d} \theta}\right)=\mathrm{atan} \frac{\mathrm{b}_{1}}{\mathrm{a}_{1}}
$$

Figure 4 essentially summarizes all of the above results. During the first 25 hours, wave energy contained in frequency bands greater than about $1 \mathrm{~Hz}$, follows the slowly turning wind. The energy distributions are unimodal as the sea smoothly adjusts to the turning wind. Immediately following the arrival of the swell (from about $120^{\circ}$ ), higher frequency waves turn away from the wind to align roughly perpendicularly to the swell (at about 10 to $30^{\circ}$ ). From this point, they roughly keep a constant, frequency dependent angle to the wind direction. This angle tends to be smaller at higher frequencies.

\section{Case 2 (C2)}

In the second case, the wind shifts by about $120^{\circ}$ in less than 6 hours, a wind shift gradient considerably higher than in the preceding case. Figure 5 presents a plot of the mean wave direction at 6 discrete frequencies, plotted with the wind direction. The plot clearly shows that the higher frequency components adjust quickly to the turning wind whereas the other low frequency components progressively react slower. Figures $6 \mathrm{a}$ to $6 \mathrm{~d}$ present the evolution of the wave energy spreading function at respective frequencies of $0.1,0.15,0.25$ and $0.35 \mathrm{~Hz}$. The $0.1 \mathrm{~Hz}$ frequency band initially turns very slightly into the wind (Figure 6a) but then becomes completely decoupled from the wind and behaves separately. The next three frequency bands behave similarly despite the fact that their 


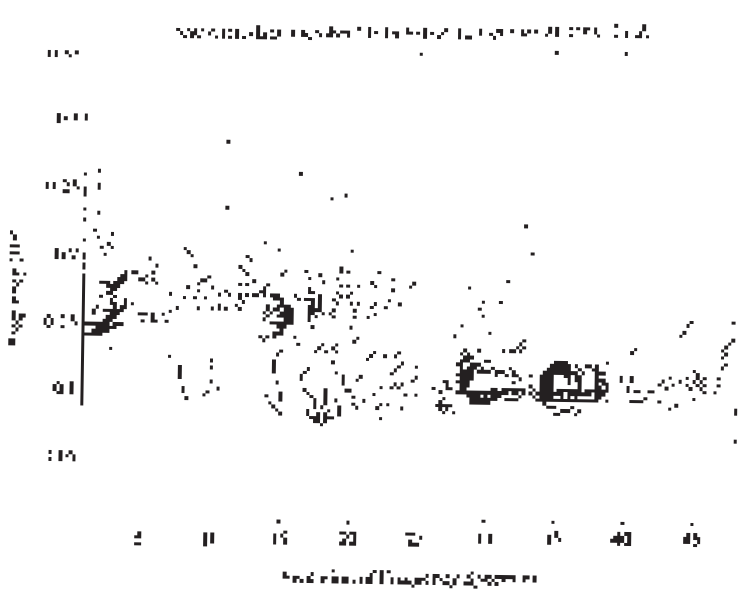

(a)

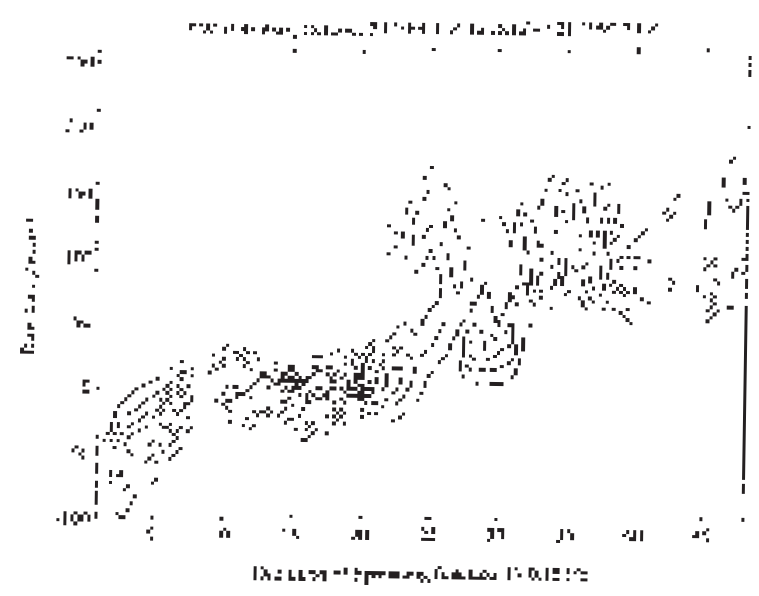

(c)

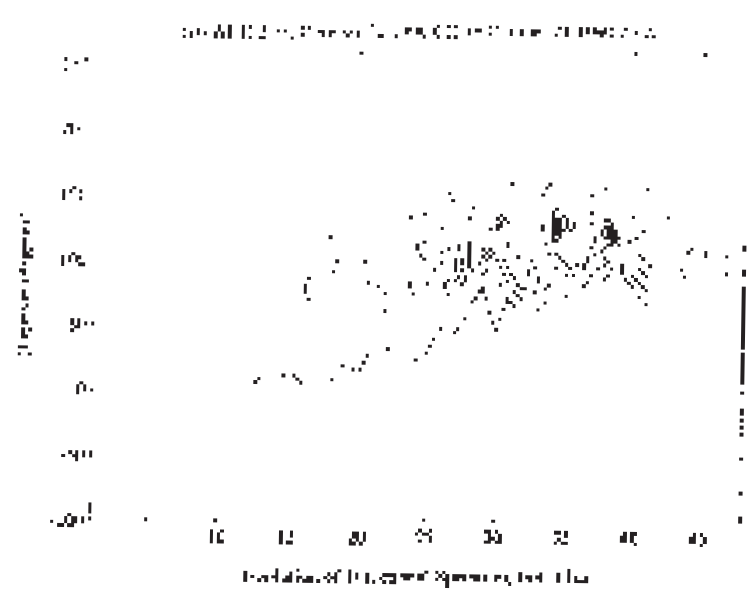

(b)

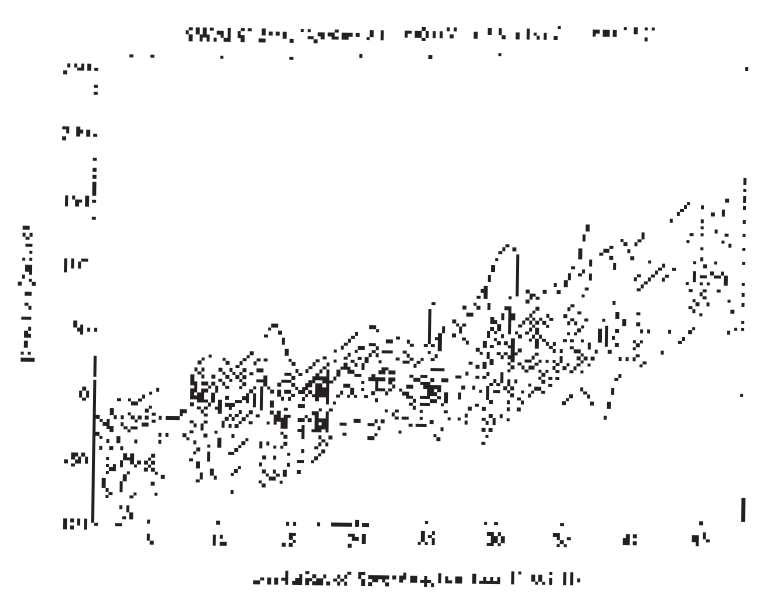

(d)

Figure 3. (a): Evolution of the frequency spectrum over the October 20-21 period. Contours are equally spaced from maximum energy to zero energy.

(b): Evolution of the directional spectrum at $\mathrm{f}=0.1 \mathrm{~Hz}$ over the October 20-21 period. Contours are equally spaced from maximum energy to zero energy. Solid line represents the wind direction.

(c): Evolution of the normalized directional spectrum (spreading function) at $\mathrm{f}=0.15 \mathrm{~Hz}$ over the October 20-21 period. Contours are equally spaced from maximum energy to zero energy. Solid line represents the wind direction.

(d): Evolution of the normalized directional spectrum (spreading function) at $\mathrm{f}=0.2 \mathrm{~Hz}$ over the October 20-21 period. Contours are equally spaced from maximum energy to zero energy. Solid line represents the wind direction.

respective relaxation time is different. The interesting common feature of those higher frequency bands (Figures 6b, 6c, 6d) can be observed at about 10 hours when the wind shift gradient reaches its maximum. At this point, instead of turning slowly toward the wind as a whole, part of the spectrum energy becomes decoupled from the wind and dissipates on its own, while the rest of the energy spectrum turns toward the wind. This effect is more apparent at lower frequencies. Most of the spectrum energy stays coupled with the wind and only bimodal distributions with a smaller secondary peak are created. 


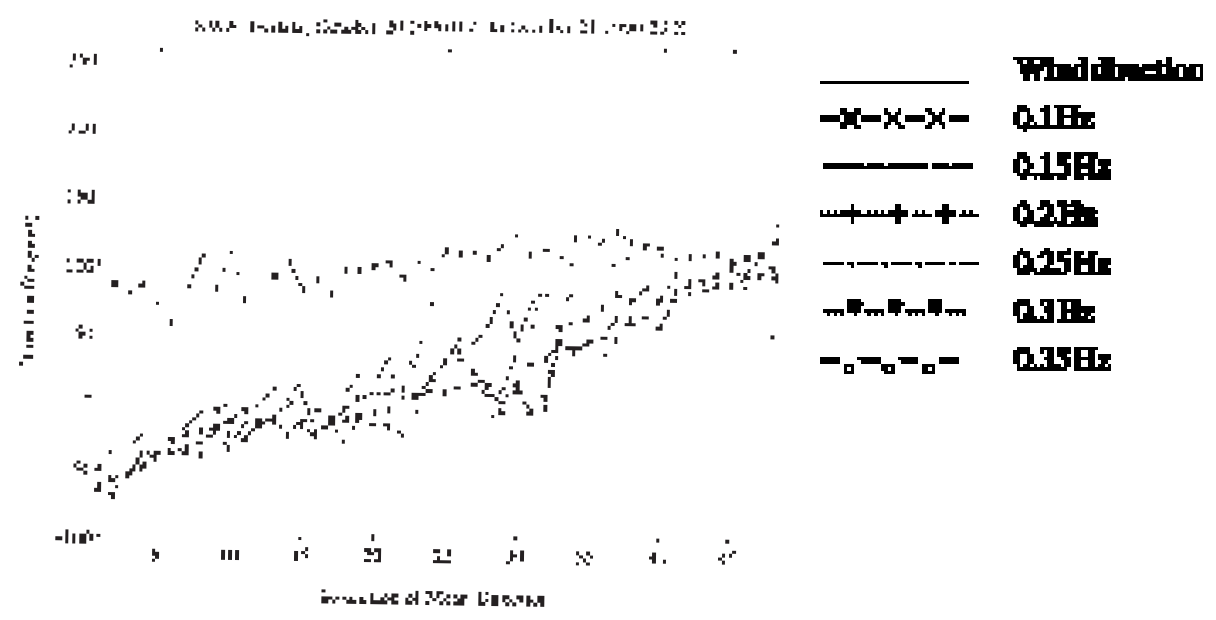

Figure 4. Evolution of the mean wave direction for various frequency bands, over the October 20-21 period.

\section{Case 3 (C3)}

The last case involves very high wind shift gradients with winds turning by as much as $150^{\circ}$ in less than 3 hours (Figure 2d). Figure 7 presents a plot of the mean wave direction at 6 discrete frequencies, plotted with the wind direction. From this plot it can be seen that the behaviour of the low and high frequency bands seems to be markedly different. The wavefield is characterized by a $50^{\circ}$ swell resulting from the previous storm (Figure 2a). The direction of the $0.1 \mathrm{~Hz}$ band is essentially unaffected during the entire 26 hours period. Figures $8 \mathrm{a}$ to $8 \mathrm{~d}$ present the evolution of the wave energy spreading function at respective frequen- cies of $0.15,0.25,0.3$ and $0.35 \mathrm{~Hz}$. Examination of Figures $8 \mathrm{a}$ to $8 \mathrm{~d}$ indicates that variations in the directional domain are markedly different than the one presented in the previous two cases. After the wind shifted rapidly, the preexisting spectra became essentially decoupled from the wind direction while a new spectrum is generated in the wind direction. The apparent different behaviour of the low and high frequency bands observed in Figure 7 is simply the result of the uncertainty linked to the calculation of a mean wave direction in cases of bimodal distributions. The observed decoupling associated with large wind shifts can create complex distributions of energy.

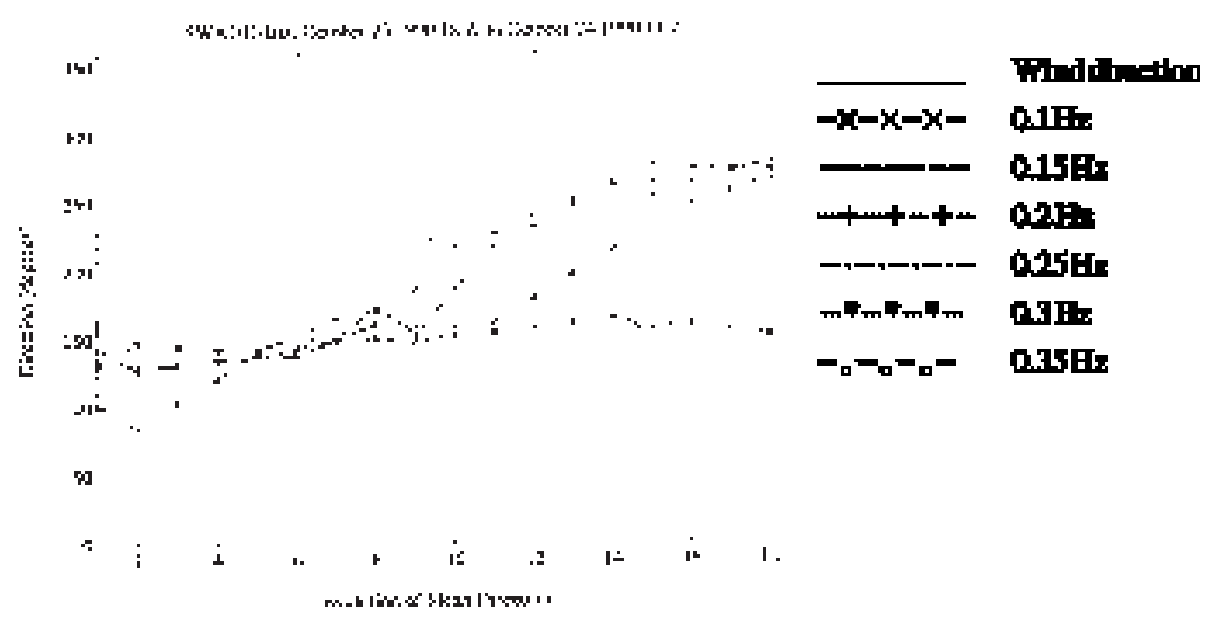

Figure 5. Evolution of the mean wave direction for various frequency bands, over the October 23-24 period. 


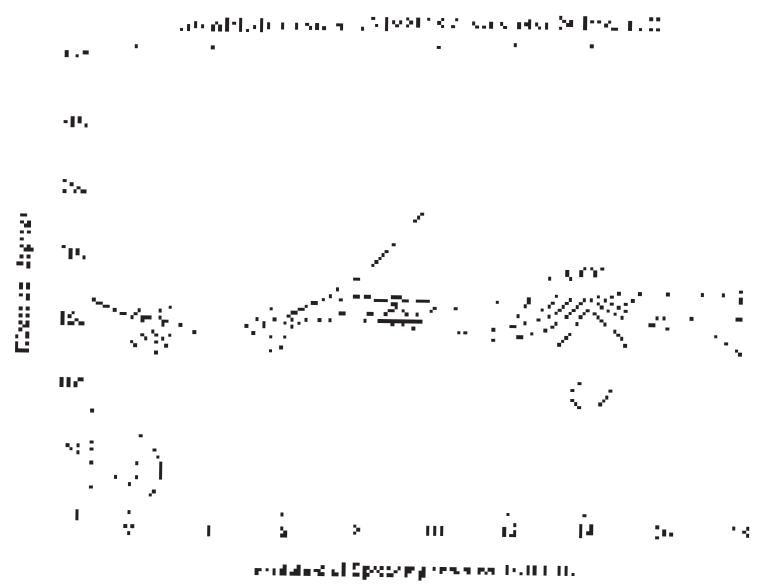

(a)

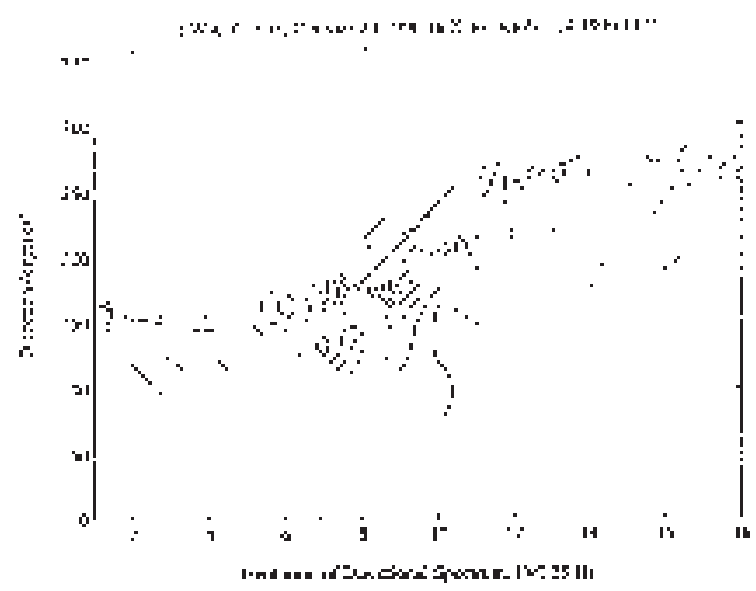

(c)

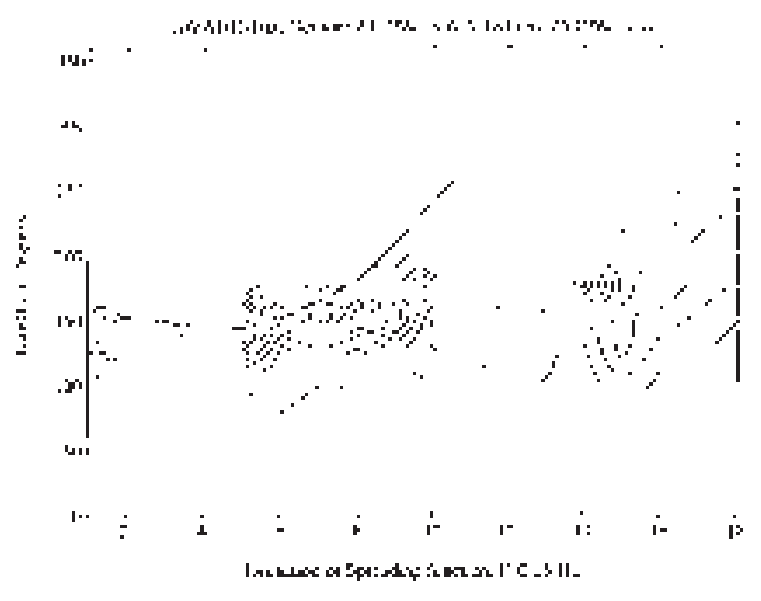

(b)

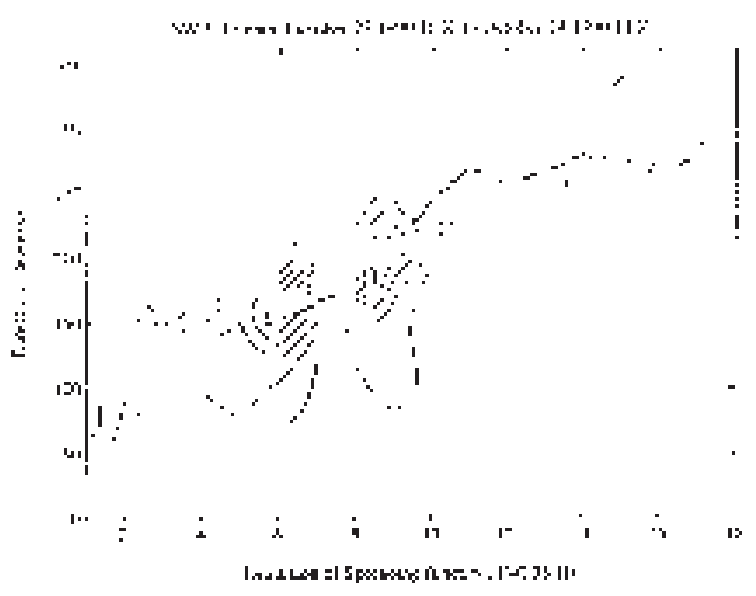

(d)

Figure 6. Evolution of the normalized directional spectrum (spreading function) at various frequencies over the October 23-24 period. Contours are equally spaced from maximum energy to zero energy. Solid line represents the wind direction.

(a): $f=0.1 \mathrm{~Hz}$; (b): $f=0.15 \mathrm{~Hz}$; (c): $f=0.25 \mathrm{~Hz}$; (d): $f=0.35 \mathrm{~Hz}$.

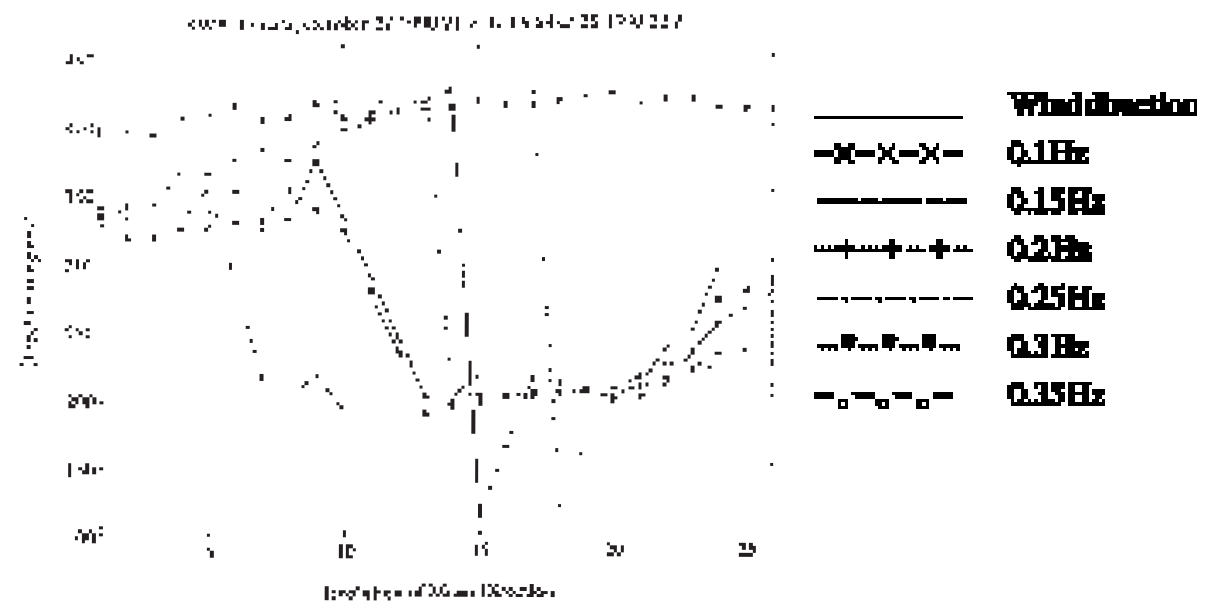

Figure 7. Evolution of the mean wave direction for various frequency bands, over the October 27-28 period. 


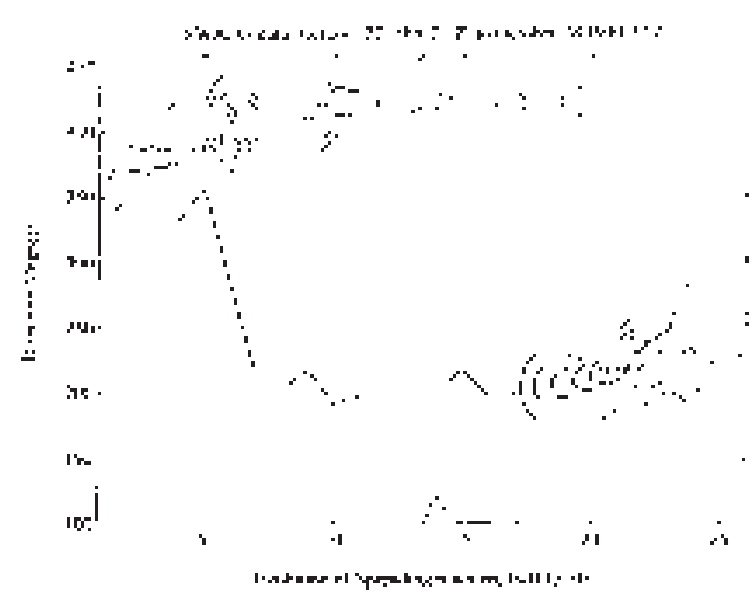

(a)

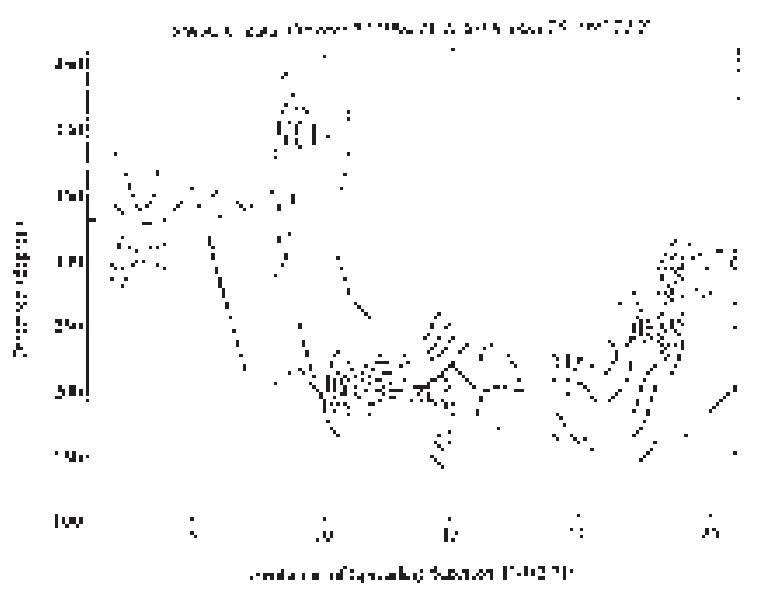

(c)

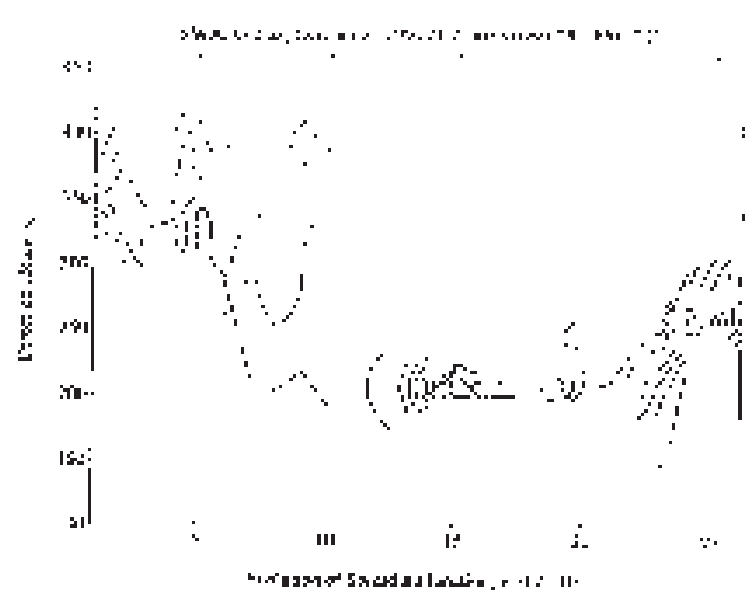

(b)

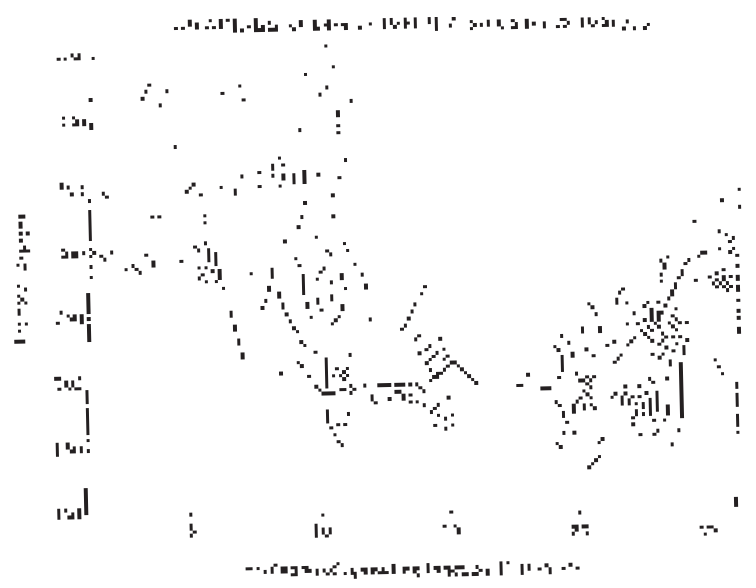

(d)

Figure 8. Evolution of the normalized directional spectrum (spreading function) at various frequencies over the October 27-28 period. Contours are equally spaced from maximum energy to zero energy. Solid line represents the wind direction.

(a): $\mathrm{f}=0.15 \mathrm{~Hz}$; (b): $\mathrm{f}=0.25 \mathrm{~Hz} ;(\mathrm{c}): \mathrm{f}=0.30 \mathrm{~Hz} ;(\mathrm{d}): \mathrm{f}=0.35 \mathrm{~Hz}$

\section{Wave directional relaxation}

The directional relaxation of waves in turning winds was investigated by Hasselman et al. (1980) with the JONSWAP data, using a simple model defined as:

$$
\frac{\partial \theta(\omega)}{\partial \mathrm{t}}=\mathrm{B} \omega \sin \left(\theta_{\mathrm{w}}-\theta_{\mathrm{m}}(\omega)\right)
$$

where $\theta_{\mathrm{m}}(\omega)$ represent the mean wave direction of a given frequency band, $\theta_{\mathrm{w}}$ is the wind direction and $\mathrm{B}$ is the relaxation parameter. Allender $e t$ al. (1983) slightly modified the form of Eq. (7) to include a dependency on the wind speed $\mathrm{U}_{\mathrm{w}}$ (measured at 10 meters) such that:

$$
\frac{\partial \theta_{\mathrm{m}}(\omega)}{\partial \mathrm{t}}=\mathrm{B}^{\prime}\left[\frac{\mathrm{U}_{\mathrm{w}}}{\mathrm{c}(\omega)}\right] \omega \sin \left(\theta_{\mathrm{w}}-\theta_{\mathrm{m}}(\omega)\right)
$$

with

$$
\mathrm{B}^{\prime} \mathrm{B}^{\prime}\left[\frac{\mathrm{U}_{\mathrm{w}}}{\mathrm{c}(\omega)}\right]
$$

and the phase speed

$$
\mathrm{c}=\frac{\mathrm{g}}{\omega}
$$

In order to compute values of Eq. (7) and to allow comparison with previously published data, the 


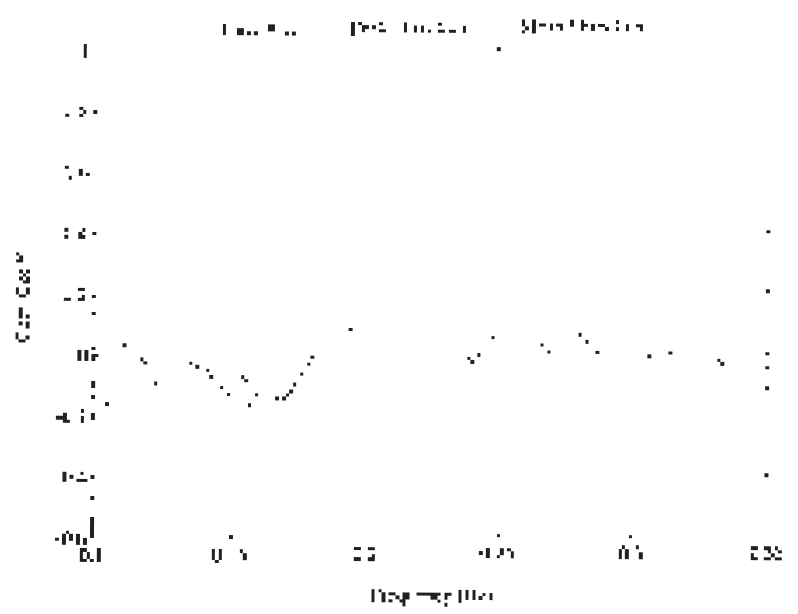

Figure 9. Correlation coefficient between the wave shifting gradient, $\partial \theta(\omega) / \partial \mathrm{t}$, (for both peak wave and mean wave directions) and $\omega \cdot \sin \left(\theta_{\mathrm{w}}-\theta(\omega)\right)($ Eq. 14), for the October 20-21 period.

wind measurements were transformed to their 10 meters value using a logarithmic velocity profile, Charnock's (1955) relationship and assuming neutral stability. To evaluate the derivative $\frac{\partial \theta_{\mathrm{m}}(\omega)}{\partial \mathrm{t}}$, a central difference scheme was used for all data except at the end points where forward and backward difference schemes were used.

The left $\frac{\partial \theta_{\mathrm{m}}(\omega)}{\partial \mathrm{t}}$ and right-hand $\left(\omega \sin \left(\theta_{\mathrm{w}}-\theta_{\mathrm{m}}(\omega)\right)\right.$ sides of Eq. (7) were computed for all frequency bands in all three cases, and correlation coeffi- cients were calculated. Figures 9 and 10 present a plot of the correlation coefficient at each frequency for $\mathrm{C} 1$ and $\mathrm{C} 3$. Eq. (7) was modeled using both the mean and peak direction of the energy distribution. It can be seen that for both cases, correlation coefficients are close to zero and no frequency dependent trend can be observed. Negative correlation coefficients are also observed.

Figure 11 presents a similar plot for $\mathrm{C} 2$. In this case, positive correlation coefficients are observed at all frequencies. The results can be seen to be significantly better when the mean

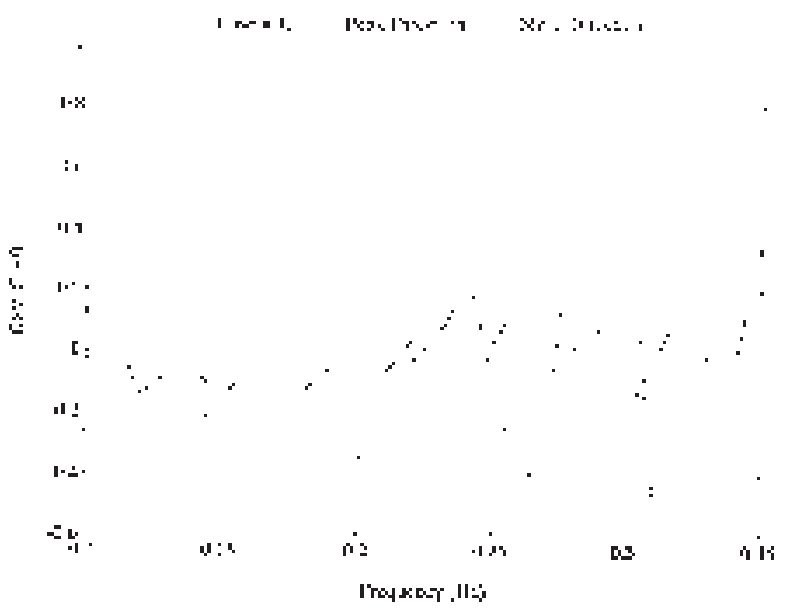

Figure 10. Correlation coefficient between the wave shifting gradient $\partial \theta(\omega) / \partial \mathrm{t}$ (for both peak wave and mean wave directions) and $\omega \cdot \sin \left(\theta_{w}-\theta(\omega)\right)$ (Eq. 14), for the October $27-28$ period. 


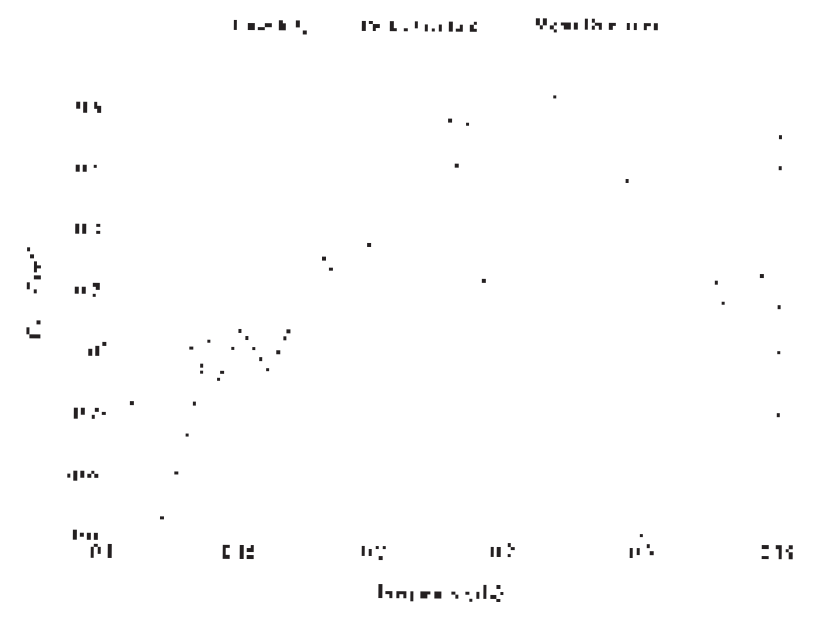

Figure 11. Correlation coefficient between the wave shifting gradient $\partial \theta(\omega) / \partial \mathrm{t}$ (for both peak wave and mean wave directions) and $\omega \cdot \sin \left(\theta_{\mathrm{w}}-\theta(\omega)\right)$ (Eq. 14), for the October 23-24 period.

direction is used as opposed to the peak direction. The correlation being significant, a one-parameter regression was computed at each frequency in order to evaluate the relaxation parameter B (the proportionality coefficient). The results presented in Figure 12 indicate that not only the regression gets better with frequency, the computed relaxation coefficient $\mathrm{B}$ gets larger with frequency, but seems to level off. In order to allow comparison with previously published data, results from $\mathrm{C} 2$ were grouped in different $\mathrm{U}_{\mathrm{W}} / \mathrm{c}$ ranges. Table 2 presents a compilation of previous results and results presented in this paper. The correla- tion coefficients obtained in this study are higher than all previous studies, especially for higher values of the inverse wave age $\mathrm{U}_{\mathrm{w}} / \mathrm{c}$.

\section{DISCUSSION}

\section{Case 1 (C1)}

This case illustrates that for sufficiently slowly turning winds, the directional spectrum adjusts very smoothly as to more or less follow the wind (Figure 4). The wind turns at a constant rate and in that case, the wave energy adjustment does not display any frequency dependent trends (the

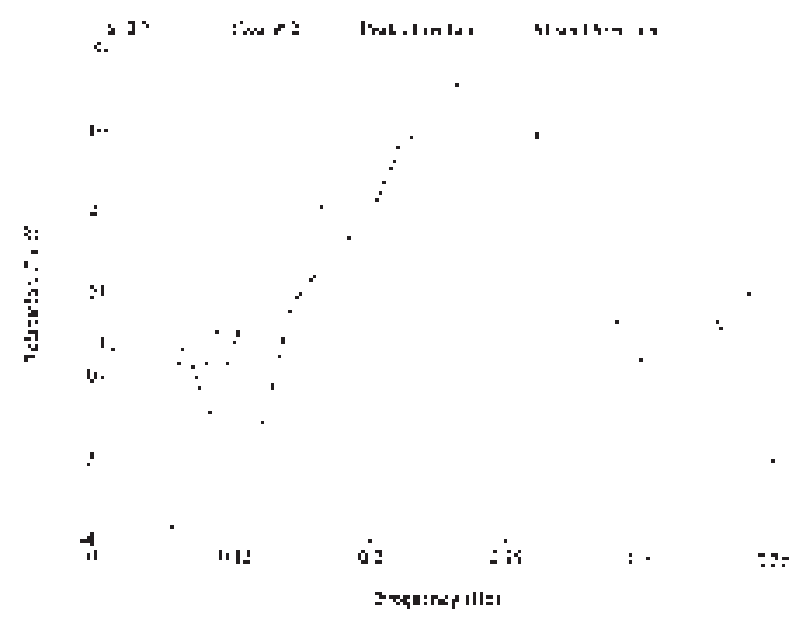

Figure 12. Values of relaxation parameter obtained for the October 23-24 period, as a function of frequency. 
Table 2. Reported Values of the Relaxation Parameter

\begin{tabular}{|c|c|c|c|c|}
\hline $\mathbf{U}_{\mathrm{w}} / \mathbf{c}$ & Entries & $B\left(\times 10^{5}\right)$ & $\mathbf{r}$ & Reference \\
\hline $1.0-1.2$ & 152 & 2.3 & 0.40 & \multirow{4}{*}{$\begin{array}{l}\text { Masson } \\
(1990)\end{array}$} \\
\hline $1.2-1.6$ & 256 & 3.8 & 0.56 & \\
\hline $1.6-2.0$ & 168 & 2.6 & 0.51 & \\
\hline $1.0-2.0$ & 576 & 3.1 & 0.55 & \\
\hline 1.6 & - & 4.3 & - & \multirow{4}{*}{$\begin{array}{l}\text { Young et al. } \\
\text { (1987)* }\end{array}$} \\
\hline 2.18 & - & 11.0 & - & \\
\hline 2.56 & - & 16.0 & - & \\
\hline $1.0-1.8$ & - & 4.0 & - & \\
\hline 1.1 & \multirow{3}{*}{$\begin{array}{c}\text { total } \\
\text { of } \\
126\end{array}$} & 1.3 & 0.25 & \multirow{3}{*}{ Allender et al. (1983) } \\
\hline 1.4 & & 1.7 & 0.25 & \\
\hline 1.8 & & 2.2 & 0.25 & \\
\hline $1.0-1.2$ & 150 & 1.6 & 0.29 & \multirow{3}{*}{$\begin{array}{c}\text { Hasselman et al. } \\
\text { (1980) }\end{array}$} \\
\hline $1.2-1.6$ & 155 & 2.4 & 0.4 & \\
\hline $1.6-2.0$ & 126 & 2.0 & 0.3 & \\
\hline $1.0-1.2$ & 54 & 2.5 & 0.18 & \multirow{6}{*}{ This study } \\
\hline $1.2-1.6$ & 108 & 5.1 & 0.49 & \\
\hline $1.6-2.0$ & 126 & 6.8 & 0.69 & \\
\hline $2.0-2.45$ & 90 & 6.6 & 0.77 & \\
\hline $1.0-1.8$ & 216 & 5.2 & 0.47 & \\
\hline $1.0-2.0$ & 288 & 5.6 & 0.52 & \\
\hline
\end{tabular}

* Experimental study with the EXACT-NL model with non-linear transfer exactly represented

relaxation rate is the same at all studied frequencies). The arrival of the swell illustrates the dramatic effect it can have on a wind sea. Low frequency swell components are little affected by the local wind whereas a definite interaction between swell and wind sea energy is observed at higher frequencies.

The tendency of higher frequency waves to align perpendicular to the swell in the early stage of its arrival is surprising. It is generally thought that interactions with a swell would have a tendency to align the wave field in the swell direction (Hasselman et al., 1980). The observations presented in this paper indicate that, at least in some cases (in all likelihood when the wind and swell directions differ by more than $45^{\circ}$ ) the wave generating component of the wind will tend to be perpendicularly aligned to the swell direction of propagation.

\section{Case 2 (C2)}

This second case shows very nicely the difference in relaxation time for the various frequency bands. The most interesting feature of this case is clearly the decoupling of part of the spectrum when the wind starts to turn rapidly. Young et al. (1987) examined the response of a wave spectrum to sudden changes in wind direction using two spectral energy balance models, the EXACT-NL model and the 3G-WAM model. Both models used the energy balance equation:

$$
\frac{\partial \mathrm{S}(\mathrm{f}, \theta, \overrightarrow{\mathrm{x}, \mathrm{t}})}{\partial \mathrm{t}}+\overrightarrow{\mathrm{c}}_{\mathrm{g}} \cdot \nabla \mathrm{S}(\mathrm{f}, \boldsymbol{\theta}, \overrightarrow{\mathrm{x}, \mathrm{t}})=\mathrm{S}_{\mathrm{in}}+\mathrm{S}_{\mathrm{nl}}+\mathrm{S}_{\mathrm{dis}}
$$

where $S(f, \theta, \vec{x}, t)$ is the directional spectrum, $c_{g}$ the group velocity, and the three terms on the 
right are the source terms respectively representing the wind input, non-linear wave-wave interaction and dissipation. The two models differed only at the non-linear wave-wave interaction level, the EXACT-NL model using the exact representation of the non-linear transfer, whereas the 3G-WAM used a discrete approximation of the transfer. Both models gave similar results for sudden changes in the wind direction ranging from $30^{\circ}$ to $180^{\circ}$. They found that for wind shifts smaller than $60^{\circ}$, the entire spectrum would adjust gradually to the new wind direction, high frequency components first, then lower frequency components. For wind shifts higher than $60^{\circ}$, a new wind sea was generated with the old sea gradually decaying into swell. To our knowledge, this has not been observed yet in field data. The minor decoupling observed in this second case might just be the representation of the onset of the phenomenon, the wind shift gradient being not quite large enough to initiate a full decoupling of the spectrum.

\section{Case 3 (C3)}

This last case pushed the analysis undertaken in the preceding case one step further by looking at even higher turning wind gradients. Results from this directional analysis confirm the work of Young et al. (1987). For sufficiently high wind shift gradients, a new spectrum will be generated while the old wind sea will decay. This was observed at all frequencies in the 0.15 to $0.35 \mathrm{~Hz}$ range. As explained by Young et al. (1987), following an examination of the source terms within their simulations, if the wind shift does not exceed $60^{\circ}$ : "the non-linear interactions prevent the growth of a secondary peak within the spectrum by coupling the peak to the already existing more stable unimodal structure". For higher wind shifts, the newly generated high-frequency peak is far away enough from the prevailing spectrum, so that the non-linear wave-wave interactions become too small to couple the new high frequency peak with the existing spectrum.

\section{Wave directional relaxation}

The simple relaxation model of Hasselman et al. (1980) presented in Eq. (7) was applied to all three cases of turning winds. Correlation coefficients were found to be essentially zero for $\mathrm{C} 1$ and C3. This indicates that the relaxation model is inadequate in explaining the observed response of the mean wave direction. The behaviour of the directional spectrum $\mathrm{C} 1$ is controlled to a large extent by the arrival of the swell, which actually forced the waves away from the wind. This effect probably masked all significant correlations that might have otherwise been measured in the absence of the swell. This points out the importance of the interaction between swell and the wind sea. Eq. (7) also implicitly assumes that the spectrum reacts smoothly to a change in the wind direction. Thus, the spectral decoupling observed in $\mathrm{C} 3$ is the expression of complex interactions that are beyond any simple relaxation model. The use of Eq. (7) to model such cases is not justifiable. Another factor that might blur the results is that in storm conditions such as the one present in late October 1990, the winds are very likely to change rapidly with distance and thus are likely to create waves coming from many directions which can enter the area of concern and interact with locally generated waves. Finally, in both $\mathrm{C} 1$ and $\mathrm{C} 3$, the wind speed is changing, adding an extra variable to an already complicated picture. Of all the three cases, only $\mathrm{C} 2$ was really fit for use with the relaxation model of Hasselman et al. (1980). The swell has little influence on higher frequency components, the wind direction changes are smooth and the wind speed is roughly constant over the duration of the event.

The computational work of Young et al. (1987) predicted wind dependence in the relaxation rate. This dependence is logically sound and simply implies that higher frequency bands will adjust more rapidly to changing winds, and the higher the winds, the faster the adjustment. This relationship was never observed before the present study. Results from C2 show a clear dependence with higher $\mathrm{U}_{\mathrm{w}} / \mathrm{c}$ values. The results also indicate that the relaxation coefficient $\mathrm{B}$ tends to reach a maximum value of roughly $7.5 \times 10^{-5}$.

Obviously, judging by the difference in the results obtained when using the peak wave direction versus the mean wave direction, one has to be careful in choosing the proper mean wave direction. The methods of computing the mean wave direction differed in the previously quoted studies. Allender et al. (1983) and Hasselman et al. (1980) (as well as this study) used the first Fourier coefficients obtained from a direct Fourier Transform in order to compute the mean wave direction. This approach, as pointed out by Borgman (1969) is equivalent to calculating the vectorial mean of the directional distribution $\mathrm{D}(\theta)$ and is arguably better than treating the directional distribution as 


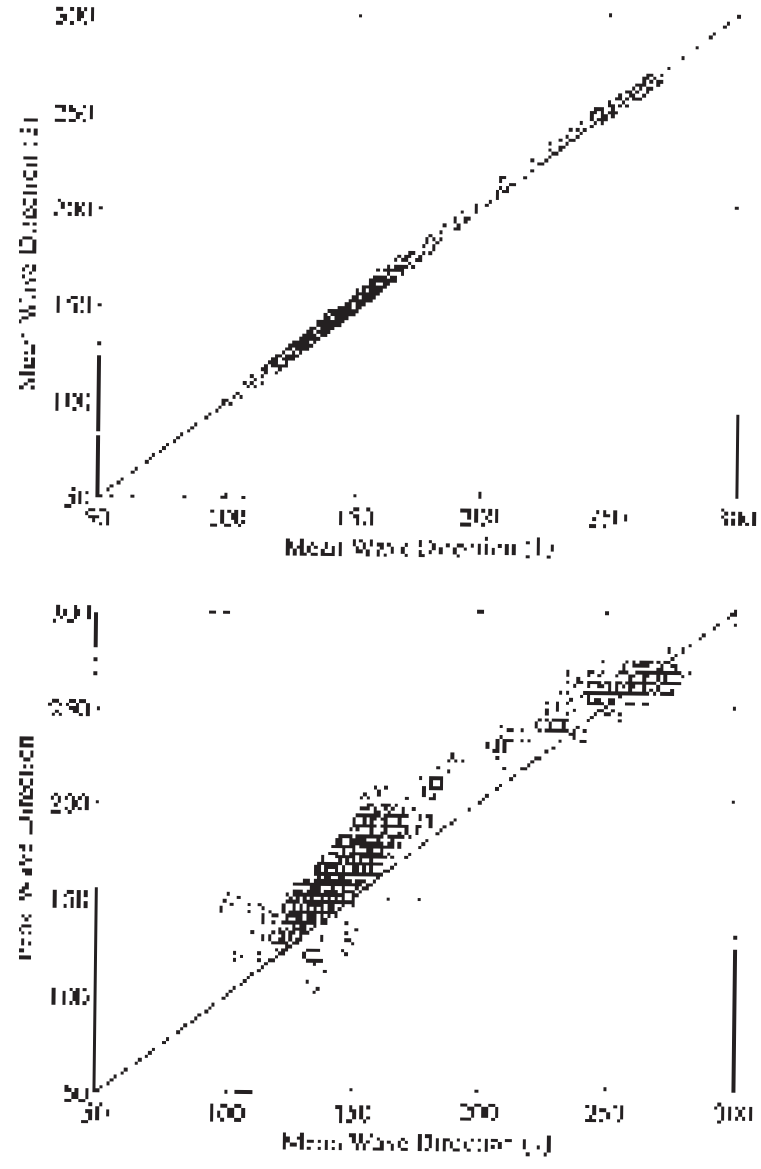

Figure 13. Top: Comparison between the mean wave direction (MWD(1)) obtained treating the directional estimate as a linear distribution (1), and using the first Fourier coefficients (2).

Bottom: Comparison between the mean wave direction and the peak wave direction. The difference between mean wave and peak wave direction indicate that the angular distributions of energy are skewed.

a linear one (as done by Masson, 1990), and calculating a mean wave direction which will be necessarily model-dependent, and thus introducing an additional variable in the system. Nevertheless, results from both methods should be similar, at least if the directional estimate is good, and the angular distribution of energy is not too asymmetrical. In order to investigate the dependence of the results on the method of calculating the mean wave direction, the mean wave direction for $\mathrm{C} 2$ was recalculated treating the directional distribution as a linear one. In such a way, if the directional spectrum at a given frequency band $\omega \mathrm{k}$ is centered around its mean direction at $\theta=0$, the following should be true:

$$
\int_{-\pi}^{\pi} \theta \mathrm{S}\left(\theta, \omega_{\mathrm{k}}\right) \mathrm{d} \theta
$$

Figure 13 presents a plot of the relationship between both mean wave directions, computed in the $0.1-0.35 \mathrm{~Hz}$ range. It can be seen that both mean wave directions are in very good agreement. Moreover, Table 3 presents correlation coefficients and values of the relaxation parameter for both cases, clearly indicating that the choice of mean wave direction has little effect on the end results. As shown in Figure 13, when comparing mean and peak wave directions, it should be noted that the directional distributions are often significantly skewed, further indicating that the equivalence of both methods of calculating the mean direction is warranted for many angular distribution of energy, and not only in cases of nearsymmetrical distributions. However, independently of the method used, the mean wave direction will not be very informative in cases of bimodal distributions. In such cases, there is a definite need to reconstruct the entire directional spectrum, and only high-resolution methods will give a true picture of the distribution. Also, one should realize that the use of the first Fourier coefficients is justifiable for calculating the mean wave direction but certainly not to reconstruct the whole directional spectrum. Masson (1990) used the IMLM, a method with great resolution potential but subject to problems linked to the iterative scheme (Brissette and Tsanis, 1994). Unless there is a way to assess the validity of a directional estimate, such as the $Q^{2}$ statistic of Long (1980), which can demonstrate the successful convergence of the IMLM scheme, results from any directional spectrum estimation method should always be interpreted carefully. Nevertheless, correlation coefficients obtained by Masson (1990) are significantly better than previous studies and comparable to the present study when the $\left[1-2 \mathrm{U}_{\mathrm{W}} / \mathrm{c}\right]$ range is considered.

In this study, correlation coefficients were found to be better when larger $\mathrm{U}_{\mathrm{W}} / \mathrm{c}$ values were considered. The lower correlations observed at lower $\mathrm{U}_{\mathrm{W}} / \mathrm{c}$ values are possibly due to the swell, which is likely to have an effect on lower frequency wave 
Table 3. Effect of mean direction on relaxation parameter

\begin{tabular}{c|c|c|c|c}
\hline \multirow{2}{*}{$\mathbf{U}_{\mathbf{w}} / \mathbf{C}$} & \multicolumn{2}{|c|}{$\int_{-\pi}^{\pi} \theta \mathrm{D}(\theta, \omega) \mathrm{d} \theta$} & \multicolumn{2}{c}{ a $\tan \left(\mathbf{b}_{\mathbf{1}} / \mathbf{a}_{\mathbf{1}}\right)$} \\
\cline { 2 - 5 } & $\mathbf{B}\left(\times \mathbf{1 0}^{\mathbf{5}}\right)$ & $\mathbf{r}$ & $\mathbf{B}\left(\times \mathbf{1 0}^{\mathbf{5}}\right)$ & $\mathbf{r}$ \\
\hline $1.0-1.2$ & 2.8 & 0.20 & 2.5 & 0.18 \\
\hline $1.2-1.6$ & 5.0 & 0.49 & 5.1 & 0.49 \\
\hline $1.6-2.0$ & 6.6 & 0.71 & 6.8 & 0.69 \\
\hline $2.0-2.45$ & 6.5 & 0.77 & 6.6 & 0.77 \\
\hline $1.0-1.8$ & 5.1 & 0.47 & 5.2 & 0.47 \\
\hline $1.0-2.0$ & 5.6 & 0.53 & 5.6 & 0.52 \\
\hline
\end{tabular}

components. No previous study was able to observe the $\mathrm{U}_{\mathrm{W}} / \mathrm{c}$ dependency predicted by Young et al. (1987) and seen in this work. Finally, it should be noted that the values of the relaxation parameter B obtained in this study are generally slightly higher than previous studies but nevertheless comparable, especially with the results of Masson (1990), and with the results of Young et al. $(1987)$ in the $\left[1-2 \mathrm{U}_{\mathrm{W}} / \mathrm{c}\right]$ range.

\section{CONCLUSIONS}

The directional spectrum response of wavefields to turning winds was investigated for three cases of turning winds with various wind shift gradients. For slowly turning winds, the spectrum was found to adjust smoothly to the wind changes. As the wind shift gradient increased, a portion of the spectrum energy was found to be decoupled from the wind while the bulk of the spectrum adjusted smoothly to the new wind direction. Finally, for even larger wind shift gradients, the preexisting spectrum was completely decoupled from the wind and decayed separately, as a new spectrum consistent with the wind direction was generated. These results confirm the theoretical results of Young et al. (1987), obtained using a third generation wave model.

The relaxation of waves in turning winds was investigated using the model of Hasselman et al. (1980). Correlation coefficients obtained in this study are higher than previously published stud- ies, and values of the relaxation parameter are observed to increase with decreasing values of the wave age. The mean wave direction was found to be a better parameter than the peak wave direction to characterize turning wavefields. The choice of the mean wave direction (defined as either the linear distribution of a computed directional estimate or as the arctangent of the first Fourier coefficients) was found to have little effect on the results.

The three cases studied clearly show that a simple relaxation model can only be used in some cases, the effect of swell being important in the evolution of wavefields and bimodal seas very likely to present with higher wind shift gradients. The results presented in this paper clearly outline the potential of the newly developed exact form of the Maximum Likelihood Method, when information on the entire directional distribution of energy is needed. This information is critical to a better understanding of the evolution of wavefields in various environmental conditions.

\section{ACKNOWLEDGEMENTS}

We thank Mark Donelan for his comments on the original version of the manuscript. We would also like to thank Patricia Monger and Todd Pfaff whose help is sincerely appreciated. The present work was financially supported by the Natural Science and Engineering Research Council (NSERC) Grant no. OGPO157914.

\section{REFERENCES}

Allender, J.H., Albrecht, J. and Hamilton, G. (1983), Observations of directional relaxation of wind sea spectra, Journal of Physical Oceanography, 13, 1519-1525. 
Borgman, L.E. (1969), Directional spectra models for design use, Offshore Technology Conference Houston, American Institute of Mining Metallurgy and Petroleum Engineering, 721-746.

Brissette, F.P. and Tsanis, I.K. (1994), Estimation of Wave Directional Spectra from Pitch-Roll Buoy Data, Journal of Waterway Port Coastal and Ocean Engineering, 120, 92-115.

Christopoulos, S., Tsanis, I.K. and Brissette, F.P. (2000), New Maximum Likelihood methods for Estimating the Wave Directional Spectra, Technika Chronika, (forthcoming).

Charnock, H. (1955), Wind stress on a water surface, Quarterly Journal of Royal Metrological Society, 81, 639-640.

Hasselman, D.E., Dunckell, M. and Ewing, J.A. (1980), Directional wave spectra observed during JONSWAP 1973, Journal of Physical Oceanography, 10, 1264-1280.

Jefferys, E.R., Wateham, G.T., Ramsden, M.A. and Platts, M.J. (1981), Measuring directional spectra with the MLM. Proceedings of Directional Wave Spectra Applications Conference, University of California, Berkeley, California, 203-219.

Kuik, A.J., Van Vledder, G.P. and Holthuijsen, L.H. (1988), A method for the routine analysis of pitch and roll buoy wave data, Journal of Physical Oceanography, 18, 1020-1034.

Long, R.B. (1980), The statistical evaluation of directional spectrum estimates derived from pitch/roll buoy data, Journal of Physical Oceanography, 10, 944-952.

Longuet-Higgins, M.S., Cartwright, D.E. and Smith, N.D. (1963), Observations of the directional spectrum of sea waves using the motions of a floating buoy, In: Ocean Wave Spectra, Prentice-Hall, New Jersey, 111132.

Masson, D. (1990), Observations of the response of sea waves to veering winds, Journal of Physical Oceanography, 20, 1876-1885.

Steele, K.E., Wang, D.W., Teng, C.C. and Lang, N.C. (1990), Directional Wave Measurements with NDBC 3meter Discus Buoys, U.S. Department of Commerce, NOAA, NDBC, Stennis Space Center, \#180401.05, 1-35.

Steele, K.E., Lau, J.C. and Hsu, Y.L. (1985), Theory and application of calibration techniques for an NDBC directional wave measurements buoy, IEEE Journal of Oceanic Engineering, 10, 382-396.

Weller, R.A., Donelan, M.A., Briscoe, M.G. and Huang, N.E. (1991), Riding the crest: A tale of two wave experiments, Bulletin of American Meteorological Society, 72, 163-183.

Young, I.R., Hasselmann, S. and Hasselmann, K. (1987), Computations of the response of a wave spectrum to a sudden change in wind direction, Journal of Physical Oceanography, 17, 1317-1338. 